\title{
Coronary artery disease after heart transplantation: clinical
} aspects

Occlusive coronary artery disease is now the main complication limiting long-term survival after heart transplantation $^{1-3}$ and also the most common indication for retransplantation. ${ }^{1}$ The reported angiographic prevalence ranges from $2 \%$ to $28 \%$ one year after transplantation, ${ }^{45}$ increasing to $40-70 \%$ by five years. ${ }^{6-8}$ Most of these patients, however, have only minor coronary stenoses or minimal luminal irregularities. ${ }^{89}$ There are as yet few data available about the rate of progression and clinical significance of these minor changes. In this issue (pages 260-5) Mullins et al report a three year survival of $60-80 \%$ after first diagnosis of coronary disease, which depends on the number of vessels involved. ${ }^{8}$ When the disease is more advanced survival rates are poor. Keogh et al ${ }^{10}$ report actuarial three year survival rates of $6 \%$ and $22 \%$ for advanced $(\geqslant 40 \%$ stenoses) triple and single vessel disease respectively.

The clinical presentation of occlusive coronary disease in transplant recipients is very different from that in other patients. The importance of relatively minor coronary occlusive disease can be substantially increased by a tendency to increased platelet aggregation ${ }^{11}$ and blood hypercoagulability caused by high serum concentrations of fibrinogen and factors VIIC and VIIIC. ${ }^{12}$ Although a few transplant patients probably do experience angina ${ }^{13}$ most will have silent ischaemia because of autonomic denervation after surgery. As with conventional coronary disease, advanced disease in the transplanted heart is associated with frequent multifocal and complex ventricular activity and sudden death. ${ }^{14}$ Progressive heart failure caused by recurrent infarction or progressive ischaemia can develop. Acute myocardial infarction in transplant recipients is usually painless although they may report dyspnoea, palpitation or sudden weakness. ${ }^{15}$ The electrocardiographic changes may be slight because of the diffuse and atypical pattern of infarction. ${ }^{15}$

Because there is no effective treatment for established coronary occlusive disease in transplant recipients prevention is an important priority. Existing studies have been retrospective and have used widely differing diagnostic criteria. They have produced few data that are directly applicable to the management of patients being given transplants today.

Effective future research will require the best methods of diagnosis and assessment of transplant related coronary disease. Existing studies have relied heavily on conventional coronary arteriography which has very serious limitations. It consistently underdiagnoses coronary disease in transplant recipients and underestimates its severity. ${ }^{616}$ Quantitative angiography has improved sensitivity particularly in detecting smooth concentric vessel narrowing. ${ }^{16}$ Intracoronary ultrasound also enables more accurate assessment of smooth concentric stenoses but the size of the probe restricts its use to large epicardial vessels. ${ }^{17}$ The widespread involvement of small vessels in transplant related coronary occlusive disease ${ }^{18}$ probably limits the usefulness of these methods of assessment that are solely anatomical.

Functional assessment by non-invasive techniques has proved disappointing with too low a sensitivity for routine use. ${ }^{19}$ Intracoronary Doppler measurement of blood flow can be readily combined with conventional angiography and this approach may provide a more comprehensive evaluation of the occlusive disease. ${ }^{20}$

Although there are few good data on which to base recommendations about patient management it seems prudent to treat hypertension vigorously, to advise patients to eat a diet low in saturated fat, and to avoid cigarette smoking and excessive weight gain. Despite these measures many recipients will continue to have "atherogenic" lipid profiles, ${ }^{21}$ and this raises the question of drug treatment for hyperlipidaemia. Unfortunately, when the very effective hydroxymethylglutaryl co-enzyme A reductase inhibitors are used in combination with cyclosporin they can occasionally cause rhabdomyolysis and renal failure and therefore may be too hazardous to be recommended for widespread use. ${ }^{22}$ The effectiveness of aspirin in other patients may encourage its use in established coronary disease but it is probably not widely appreciated that its effectiveness is seriously limited by changes in platelet aggregation in transplant patients. ${ }^{11}$

Some centres have advocated steroid-free maintenance immunosuppression ${ }^{23}$ to reduce coronary disease. It may be particularly effective in children ${ }^{24}$ and is also desirable for their optimum growth. In adults, however, its effectiveness is unproven, and given the suspected immunological nature of the process this approach may be deleterious. The preliminary results of a randomised trial of diltiazem in the prevention of graft coronary disease from the Stanford group $^{25}$ are encouraging but further data are needed before it can be recommended for routine practice. In animal models low molecular weight heparin, which reduces smooth muscle cell proliferation, has been shown to reduce the severity of occlusive disease. ${ }^{26}$

What are now required are large scale, multicentre, randomised, prospective trials of management strategies with clearly defined end points. Advanced assessment techniques such as those discussed would be preferable. Intensive drug treatment of hyperlipidaemia, steroid-free maintenance immunosuppression, and the prophylactic use of calcium antagonists or low molecular weight heparin would be suitable for this type of study. The role of cardiac autograft rejection also needs to be investigated further particularly with reference to the question of maintenance steroid therapy. Because the United Kingdom has a relatively small number of centres, each performing substantial numbers of transplants, we are in an ideal administrative position to undertake such studies.

CHRISTOPHER D SCOTT JOHN H DARK

Freeman Hospital,

Newcastle upon Tyne

1 Kriett JM, Kaye MP. The Registry of the International Society for Heart and Lung Transplantation: Eighth Official Report, 1991. J Heart Lung Transplant 1991;10:491-8.

2 Billingham ME. Graft coronary disease: the lesions and the patients. Transplant Proc 1989;21:3665-6.

Bieber CP, Hunt SA, Schwinn DA, et al. Complications in long term survivors of cardiac transplantation. Transplant Proc 1981;13:207-11. 
4 O’Neill BJ, Pflugfelder PW, Singh NR, et al. Frequency of angiographic detection and quantitative assessment of coronary arterial disease one and three years after cardiac transplantation. Am J Cardiol 1989;63:1221-5.

5 Balk AHMM, Linden MVD, Meeter K, et al. Is there a relation between transplant coronary artery disease and the occurrence of CMV infection? [Abstract]. J Heart Lung Transplant 1991;10:188.

$6 \mathrm{Gao}$ SZ, Schroeder JS, Alderman EL, et al. Prevalence of accelerated coronary artery disease in heart transplant survivors. Circulation coronary artery disease

7 Narrod J, Kormos R, Armitage J, et al. Acute rejection and coronary artery disease in long term survivors of heart transplantation. J Heart Lung Transplant 1989;8:418-20.

8 Mullins PA, Cary N, Sharples L, et al. Coronary occlusive disease and late graft failure after cardiac transplantation. Br Heart $J$ 1992;68:260-5.

9 Uretsky BF, Murali S, Reddy S, et al. Development of coronary artery disease in cardiac transplant patients receiving immunosuppressive therapy with cyclosporine and prednisone. Circulation 1987;76:827-34

10 Keogh A, Valantine H, Hunt S, et al. Impact of transplant coronary artery disease on survival after cardiac transplantation [Abstract]. $J$ Heart Lung Transplant 1991;10:172.

11 de Lorgeril M, Dureau G, Boissonnat $P$, et al. Increased platelet aggregation after heart transplantation: influence of aspirin. $J$ Heart Lung Transplant 1991;10:600-3.

12 Hunt BJ, Segal H, Yacoub M. Haemostatic changes after heart transplantation and their relationship to accelerated coronary sclerosis. Transplant Proc 1991;23:1233-5.

13 Schroeder JS, Hunt SA. Chest pain in heart transplant patients. N Engl J Med 1991;324:1805-6.

14 Romhilt DW, Doyle M, Sagar KB, et al. Prevalence and significance of arrhythmias in long-term survivors of cardiac transplantation. Circulation 982;66(suppl I):219-22.

15 Gao SZ, Schroeder JS, Hunt SA, et al. Acute myocardial infarction in cardiac transplant recipients. Am J Cardiol 1989;64:1093-7.
16 Gao SZ, Alderman EL, Schroeder JS, et al. Progressive coronary luminal narrowing after cardiac transplantation. Circulation 1990;82(suppl IV):269-75

17 Pinto FJ, StGoar FG, Alderman EL, et al. Intracoronary ultrasound evaluation of coronary artery disease in cardiac transplant recipients: a new "gold standard"? [Abstract]. Proceedings of European Society for Organ Transplantation 1991:141.

18 Gao SZ, Alderman AL, Schroeder JS, Silverman JF, Hunt SA. Accelerated coronary vascular disease in the heart transplant patient: coronary

19 Smart FW, Ballantyne CM, Cocanougher B, et al. Insensitivity of noninvasive tests to detect coronary artery vasculopathy after heart transplanta vasive tests to detect coronary artery

20 Mullins P, Scott J, Aravot D, et al. Small vessel coronary occlusive disease after cardiac transplantation [Abstract]. J Am Coll Cardiol 1991;17:308.

21 Stamler JS, Vaughan DE, Rudd A, et al. Frequency of hypercholesterolaemia after cardiac transplantation. Am J Cardiol 1988;62. 1268-72.

22 Corpier CL, Jones PH, Suki WN, et al. Rhabdomyolysis and renal injury with lovastatin use. Report of two cases in cardiac transplant recipients. $J A M A$ 1988;260:239-41.

23 Ratkovec RM, Wray RB, Renlund DG, et al. Influence of corticosteroid-free maintenance immunosuppression on allograft coronary disease after cardiac transplantation. J Thorac Cardiovasc Surg 1990;100:6-12.

24 Radley-Smith R, Yacoub $M$. Low incidence of accelerated coronary sclerosi in children undergoing cardiac transplantation maintained on cyclosporin and azathioprine only [Abstract]. J Am Coll Cardiol 1991;17:102.

25 Schroeder JS, Gao SZ, Alderman EL, Hunt SA, Stinson EB. Diltiazem inhibits development of early coronary arterial narrowing in cardiac inhibits development of early coronary arterial narrowing

26 Aziz S, Tada Y, Verrier E, Fareed J, Gordon D. Reduction in accelerated graft atherosclerosis by low molecular weight heparin plus cyclosporin [Abstract]. J Heart Lung Transplant 1992;11:211. 